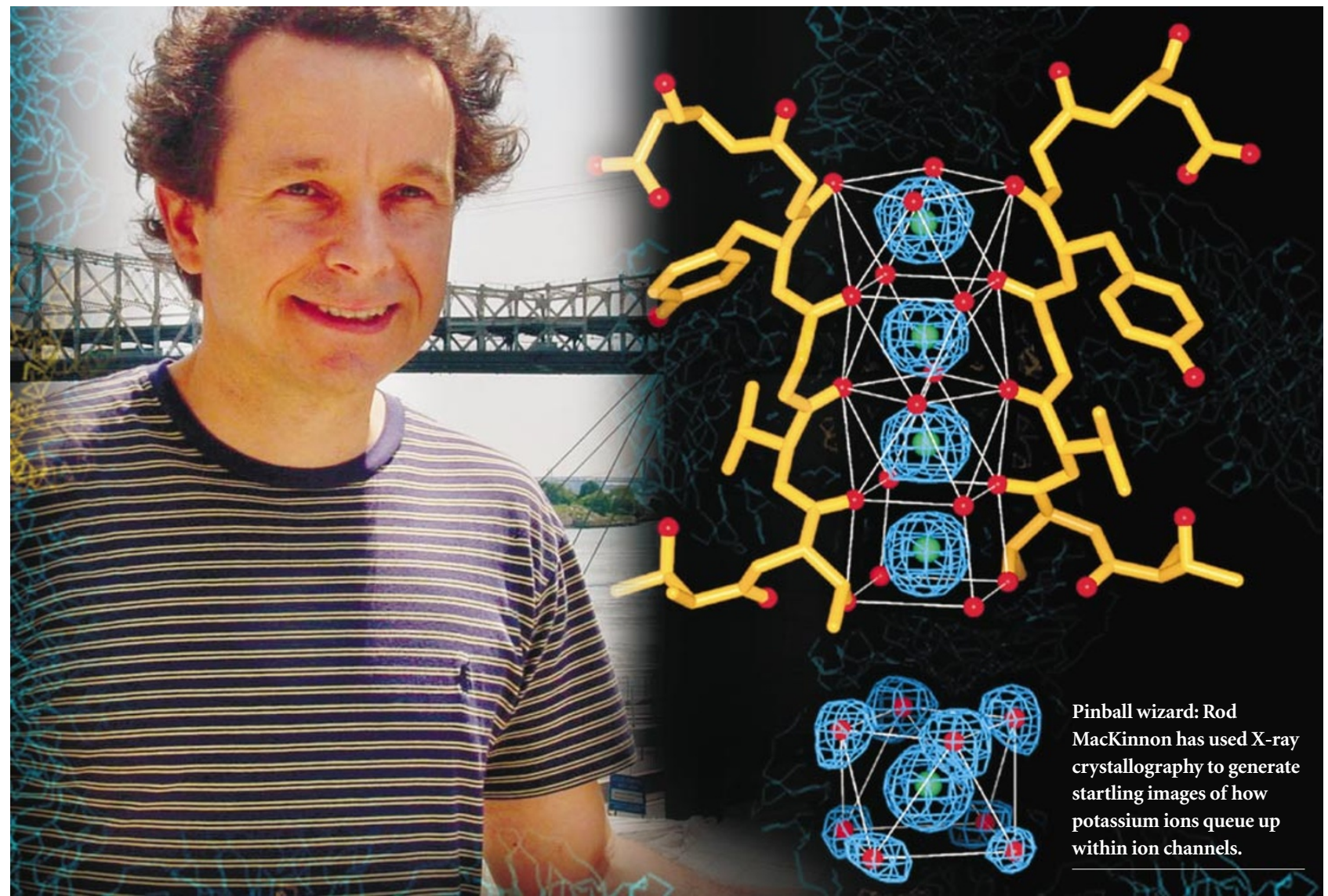

\title{
They said it couldn't be done...
}

\section{Determining the structure of cell-membrane ion channels was thought to} be mission impossible. Alison Abbott meets the researcher who proved the doubters wrong, opening new windows on cellular function.

20 od MacKinnon woke up on 1 January 1998 with a sickening feeling that his eureka moment had been a dream. Late into the night, at Cornell University's synchrotron light source in Ithaca, New York, he had been processing data on the structure of a crystallized potassium-ion channel from a cell membrane. Eventually, his colleagues left to join the New Year celebrations, and MacKinnon worked on alone.

Midnight passed, and with each iteration of the data, the image of the channel on his computer screen became clearer. Then, in the channel, shadows of multiple potassium ions began to emerge, lined up like pinballs, exactly as had been predicted some 50 years earlier. "I became so shaky I couldn't hit the keys, and I had no one to tell," MacKinnon recalls. Eventually he went to bed, the excitement of his discovery still buzzing round his head.

Fortunately for MacKinnon, this was no dream. It was, in fact, a stunning highlight among a series of revelations about ion channels to emerge from his lab. And it was all the more remarkable for the fact that, when MacKinnon embarked on his quest to unveil the channels' structures just a few years before, many structural biologists had regarded him as foolhardy. Didn't he realize that ion channels were almost impossible to crystallize for X-ray structural analysis?

Ion channels are proteins embedded in cell membranes. They act as extremely selective gateways, allowing specific ions to pass in and out of the cell in response to various signals. Most dramatically, they mediate the electrical impulses known as action potentials that are the basis of communication in the nervous system.

\section{became so shaky I \\ couldn't hit the keys, and I had no one to tell.}

MacKinnon didn't start out obsessed with ion channels. After gaining a biochemistry degree, he studied medicine, but soon found that his enquiring mind required a tougher challenge. "I needed to do a real science," he says. So in 1986, MacKinnon returned to Chris Miller's laboratory at Brandeis University in Boston, where he had worked on an undergraduate project, to retrain as an electrophysiologist. This soon lured him towards the mysteries of potassium-channel function.

These puzzles had their roots in the pioneering studies of Alan Hodgkin and Andrew Huxley at the University of Cambridge, UK, who in 1952 showed that a nerve cell's membrane becomes transiently, and very rapidly, permeable to sodium at the start of an action potential ${ }^{1}$. Sodium ions rush into the cell, causing the voltage across the membrane to drop. The membrane then becomes permeable to potassium ions, which flow out of the cell, allowing it to return to its resting potential.

Three years later, Hodgkin, with his col- 
league Richard Keynes, looked at the flow of radioactive potassium ions across the membrane of a nerve cell. They concluded that ions must be "constrained to move in a single file, and there should, on average, be several ions in the channel at any moment" ${ }^{2}$. MacKinnon got an enormous kick out of finally being able to show that this prediction was correct ${ }^{3}$. "I love the way Hodgkin thought," he says.

In the decades before MacKinnon entered the field, Hodgkin and his successors showed that fluxes of ions across cell membranes are mediated by distinct channels, regulated by sensors that respond to particular environmental cues. Some potassium channels, for instance, respond to changes in voltage across the membrane, whereas others react to the presence of neurotransmitter chemicals.

\section{Channelled energy}

The problem of exactly how potassium channels open and close became MacKinnon's preoccupation. Having moved to Harvard University in 1989, MacKinnon raced up the academic ladder to become a full professor in 1995. A year later he relocated to New York's Rockefeller University, where he is now a Howard Hughes Medical Institute investigator.

Initially, MacKinnon used electrophysiological techniques to study the properties of potassium channels from bacteria. By mutating the channels at key points and looking at how this changed their properties, he was able to reveal many of their secrets. He showed, for example, that a potassium channel consists of four subunits surrounding a central pore ${ }^{4}$, and was also able to determine which amino acids are responsible for its selectivity - allowing potassium through but blocking other ions ${ }^{5,6}$.

But these results prompted questions that electrophysiology and mutagenesis could not answer. How are the subunits arranged in three dimensions? What is the precise atomic structure that confers such exacting selectivity? To get the answers, MacKinnon needed to become an X-ray crystallographer. So he started reading books on the subject, and haunting the lab of Harvard crystallographer Steve Harrison. "The postdocs and students thought it was odd, having a professor hanging around, but they got used to it - and they really were my mentors," says MacKinnon.

Colleagues advised MacKinnon against embarking on what they feared would be an impossible journey. Miller, currently working on sabbatical in MacKinnon's lab, told him bluntly: "You're out of your mind."

When MacKinnon moved to Rockefeller to begin his new life as a crystallographer, only one of his existing postdocs, Declan Doyle, went with him. "We had a great time," says Doyle, who now runs his own lab at the University of Oxford, UK. The move coincided with the advent of a highly efficient system for expressing potassium ion channels in bac-

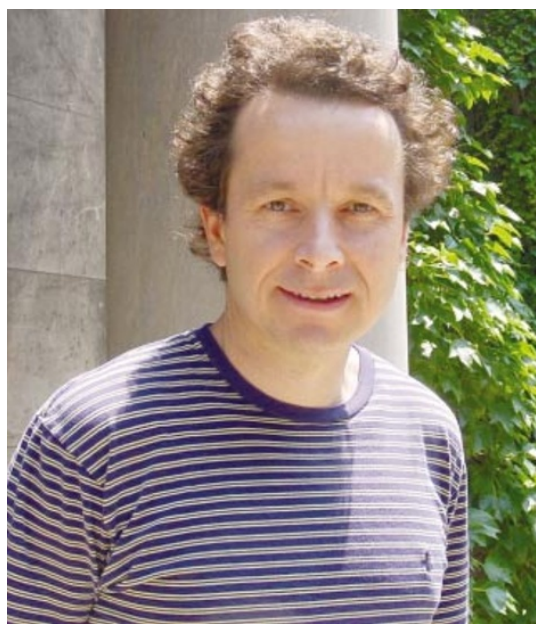

$W^{\text {resendare }}$ is easy to pay attention to all the details.

teria ${ }^{7}$, which offered the crystallographers the large amounts of protein that they needed.

After an initial quiet period, the papers started pouring out. In 1998, MacKinnon and his colleagues published their landmark three-dimensional structure of a potassium ion channel. ${ }^{3}$. In the past two years, the researchers have gone on to show how a potassium channel opens by bending its inner helix at a hinge point ${ }^{8}$. They have also revealed the structural elements within certain potassium channels that interact with the sensors that regulate their activity ${ }^{8,9}$ - not to mention two papers last year that revealed the channels' workings in fine detail ${ }^{10,11}$.

\section{Passionate blend}

Why has MacKinnon succeeded where others failed? "Just a dogged determination, and passion - when you are passionate it is easy to pay attention to all the details," he says. But this success required a lot of care and patience. "Ion channels need to be extracted along with those lipids that support their structure, and crystallized before they dissociate," MacKinnon says. Fortunately, his experience as an electrophysiologist provided him with the tools - such as toxins that bind to particular sites on a channel - to check at each stage of sample preparation whether the channels are still functional. "You have to keep asking your protein: 'Are you OK?'” he says.

MacKinnon's highly focused team of ten or so postdocs and students is also central to his modus operandi. He endlessly discusses experimental design and the significance of results with lab members - who are very much hand-picked. "When I see promising candidates on paper, I invite them to spend a day in the lab," says MacKinnon. "I talk to them for hours, trying to see if they have a scientific mind." Then he throws them in with his young colleagues to see how they get on. "When you spend so much time together it is important that they have a happy working environment."

Many subtle ingredients have also contributed to MacKinnon's success. Foremost, perhaps, is the fearlessness that allowed him to leap, inexperienced, at a powerful research tool. "It is better to crash and burn than never to have tried," he says.

Then there is his love of puzzle-solving. In his leisure time, MacKinnon reads books on the history of mathematics and science in the way that others might read thrillers. "I like to work out how scientists in the past came across the problems they solved, and how exactly they approached their problems." Suddenly he is seized by embarrassment: "Oh, that may seem a bit nerdy."

And notwithstanding aberrations such as his lab marathon on New Year's Eve, MacKinnon also tries to keep his life in balanceretreating whenever he can to his summer house in Cape Cod, where he indulges his passions for fly fishing and swimming.

Today, MacKinnon's office, with its fine view of the 59th Street Bridge and the East River, is littered with prizes. Foremost among them is his 1999 Lasker award. Given that around $50 \%$ of Lasker winners go on to win a Nobel, colleagues wonder whether MacKinnon will one day emulate his intellectual hero Hodgkin, and receive that call from Stockholm. He has rehearsed his response to such speculation: "What I always tell people is that half of those who get the Lasker don't go on to win the Nobel."

Ion channels still have some challenges to offer - MacKinnon is keen to crack the secrets of a particularly recalcitrant potassium channel that is regulated by the voltage across the cell membrane. But at the age of 46 , he is thinking of another shift in direction. "Once passion is spent it is time to move on, otherwise you start to overlook details," he says.

What might that new direction be? MacKinnon says he has a few ideas, but for now he is keeping them to himself. Given what he achieved after switching from electrophysiology to structural biology, however, many biologists would dearly love to know what is next on his agenda.

Alison Abbott is Nature's senior European correspondent.

1. Hodgkin, A. L. \& Huxley, A. F. J. Physiol. 117, 500-544 (1952).

2. Hodgkin, A. L. \& Keynes, R. D. J. Physiol. 128, 61-88 (1955).

3. Doyle, D. A. et al. Science 280, 69-77 (1998).

4. MacKinnon, R. Nature 350, 232-235 (1991).

5. MacKinnon, R. \& Miller, C. Science 245, 1382-1385 (1989).

6. Heginbotham, L., Lu, Z., Abramson, T. \& MacKinnon, R. J. Biophys. 66, 1061-1067 (1994).

7. Schrempf, H. et al. EMBO J. 14, 5170-5178 (1995).

8. Jiang, Y. et al. Nature 417, 515-522 (2002).

9. Zhou, M., Morais-Cabral, J. H., Mann, S. \& MacKinnon, R. Nature 411, 657-661 (2001).

10. Morais-Cabral, J. H., Zhou, Y. \& MacKinnon, R. Nature 414, 37-42 (2001).

11.Zhou, Y., Morais-Cabral, J. H., Kaufman, A. \& MacKinnon, R. Nature 414, 43-48 (2001). 